\title{
Bureaucrats pose threat to museums
}

Sir-Your article on the funding difficulties of Seattle's Burke museum, and its bid for independence, illustrates a common problem faced by university natural history museums (Nature 399, 189; 1999). The article also mentioned the 100year-old Sam Noble Oklahoma Museum of Natural History - the largest repository of Oklahoma's heritage. As I was offered the directorship of the Burke and have been director of the Sam Noble museum for 17 years, my views may be germane.

Today, university presidents are selected from a rotating pool of administrators who no longer have a deep understanding of a particular campus. They do not possess any special institutional loyalty. If they avoid offending the governing board, raise enrolment, and increase income, they will succeed. Soon they will move to a more prestigious position. A museum's future hinges on decisions made by these transient administrators, but what can heritage mean to such a person, and how can such a transitory bureaucrat be expected to deal with the special needs of an enduring institution?

The intangible value of scholarship by museum curators, educational benefits for students, and public outreach are small change for administrators focused on costs and benefits. Their concerns are the high cost of storing collections, the low funding for museum research, the decline of taxonbased classes that require specimens, and the low public profile of campus museums. Does the museum produce credit hours to justify more funds? Does it make money? Does it have public support that could cause political problems? The answer to each is usually 'No'.

Nevertheless, one hears remarkable success stories. The University of Oklahoma has built an outstanding $\$ 44$ million building (www.snomnh.ou.edu), although Oklahoma is a poor state. We, too, were told that a new museum was impossible, but we took the project to the people and drew on their power for support.

University museums, as keepers of the nation's heritage, must develop a long-term strategy that calls on their constituents to understand and support their purposes. It is dangerous for a museum to pull away from its university. Will a private board understand the importance of collections when not used for teaching and research? Will it only be interested in exhibits? Will it see the need for curators?

University museums provide leading scholars in disciplines from systematics to conservation. They train the scientists of tomorrow. Museums must not lose sight of their unique role - to preserve and interpret heritage, contribute knowledge, and educate students and the public. Leaving the university violates the museum's raison d'être. The present administrators will soon be gone, but the people - the ultimate supporters - will remain. Museums are forever.

Michael A. Mares

Sam Noble Oklahoma Museum of Natural History, University of Oklahoma,

Norman, Oklahoma 73072, USA

\section{What price 'prestige' in publishing?}

Sir - I support Mark Riley in his protest against the outrageous price increases of some journals, but I do not think that all the blame rests with the commercial publishers (Nature 399, 623; 1999). They are in the business of making profits. We should ask ourselves why the scientific community lets these people run our research journals to their, rather than our, advantage.

The answer is in the fallacious system of 'journal prestige' which scientists have created. Nothing stops us from communicating our research results through less costly systems, such as preprints, electronic self-publishing, and small-scale journals run by interest groups.

But, unless a paper is published in a 'prestigious' journal, it does not count for much for grants, promotions, invited talks, and so on. This is how we let commercial publishers keep a grip on our throats. It is within our capacity to change it, if we wish. And, unless we do so, the commercial publishers cannot be blamed if they run our business as they see fit.

Although perceptual changes will be difficult to achieve by legislation from above, some much-needed adjustment in the research community can be started at the grassroots level. For example, any 'official' use of journal prestige ranking should be resisted or drastically minimized. Our obsession with numerical ranking of almost everything has gone too far and often brings more harm than good.

Second, the research funding system should encourage publication in local journals. In Canada, for example, it is considered almost a disgrace to publish in the 'Canadian Journal of XYZ' in some disciplines. Pressure to publish in only some celebrated journals has become an unhealthy obsession fuelled by the reward system in academic institutions.

Finally, the idea of discount publishing at the lowest possible commercial rates should be considered.

Alexander A. Berezin

Department of Engineering Physics, McMaster

University, Hamilton, Ontario, Canada L8S $4 L 7$

\section{Icelanders opt out of}

\section{genetic database}

Sir - In a News article ${ }^{1}$ the ethical guidelines for a Swedish biobank were compared to the lack of ethical considerations in the Health Sector Database (HSD) law in Iceland. The Icelandic project, proposed by deCODE Genetics, Inc, fares poorly in the comparison, mostly because the law permits the granting of an exclusive licence to a single company to do genetic and other research on the whole-population database, without requiring informed consent. Instead the term presumed consent is introduced, leaving an opting-out possibility for those who fill in the correct forms.

Jeffrey Gulcher and Kari Stefansson of deCODE object to the comparison ${ }^{2}$. Some inaccuracies in their letter deserve correction. First, they state that, according to the HSD law, medical information can be linked to genealogy and genetic information only with informed consent. But informed consent is not mentioned in the law ${ }^{3}$. No ethics committee will have the authority to require consent, unlike in the Swedish project.

Second, they state that "the bill grants deCODE the exclusive right to market this anonymous database outside Iceland, but not the exclusive right to use the database". This is also incorrect. Although the HSD law was sponsored by deCODE the company is not mentioned in it, and the licence has not been granted yet. More importantly, the database will not be anonymous since it will contain personal identifiers which, although encoded, can be used to identify individuals ${ }^{4}$.

Third, the law grants the licensee the exclusive rights to create and operate the database, and says nothing about the access of other researchers, contrary to what Gulcher and Stefansson claim.

Fourth, the authors say that "deCODE obtained its licence to construct and run the 
health-care database through the democratic process". But important changes were made to the bill in parliament, without debate. For example, the bill now allows the licensee to connect the medical database to a genetic database, without requiring informed consent. The warnings of nearly all the independent expert groups that were asked to comment on the bill were ignored $^{3}$. Our small society was not able to withstand deCODE's expensive information campaign.

Now the state-controlled banks have purchased almost half of the US venture capitalists' original investment in deCODE, increasing concern about the close ties between deCODE and the government.

The European Union's Data Protection Commissioners recommended that the Icelandic authorities should reconsider the project in the light of the European Convention on Human Rights. This was not done, and the consequences are lack of consent, lack of traditional ethics control and lack of freedom to withdraw information entered into the database.

More than 11,000 Icelanders have opted out of the HSD database. Many doctors have promised not to send information about patients to the database, so we believe it will not be created as originally envisaged. Sweden's UmanGenomics seems to be doing a much better job.

\section{Pétur Hauksson}

Mannvernd, Association for Ethics in Medicine and Science, PO Box 94, Reykjavik 112, Iceland

Sir - Gulcher and Stefansson's letter ${ }^{2}$ is a striking demonstration of the corporate culture of companies such as deCODE Genetics and British Biotech, and their difficulty in telling the story straight ${ }^{5}$.

To assert that the HSD law was approved through a democratic process underestimates the steamrollering power of a large government majority. Warnings from the Icelandic Medical Association, local and international geneticists, and privacy experts were ignored. The speed of the Icelandic legislative process precluded balanced and informed analysis of a complicated issue. It is sheer spin-doctoring to suggest that this over-speedy, illthought-through legislation expresses informed community consent.

Using encrypted identifiers for a comprehensive dynamic database describing the health status, genealogy and genotype of a population without informed consent opens up an ethical Pandora's box. Skúli Sigurdsson Institute of Cultural Studies, Humboldt University, Sophienstrasse 22a, 10178 Berlin, Germany

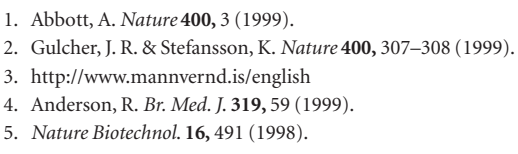

\section{Corals resist extinction by global warming}

Sir - Coral reefs form complex ecosystems that easily reflect changes in environmental conditions. It is therefore alarming that many reefs show signs of bleaching, which can be interpreted as the beginning of degeneration. Peter Pockley reports that experts ascribe the degeneration to global warming, and predict the disappearance of most reefs within a century (Nature 400, 98; 1999). This prediction may be based on biological considerations, but it seems to contradict geological data.

Coral reefs have survived geological periods with considerably higher - and others with considerably lower temperatures than we face now or in the near future. The reefs also survived sea level fluctuations between more than 10 metres above the present level and more than 100 metres below. So it appears from geological history that corals - like most organisms - are well capable of adapting to changing environments, even though they may be less flourishing during a period of change.

The geological past shows that global warming in itself is not a threat to reefs.

\section{A. J. (Tom) van Loon}

Geocom, P. O. Box 336, 6860 AH Oosterbeek, The Netherlands

\section{'Snowball Earth' theory still stands}

Sir - George Williams ${ }^{1}$ defends the highobliquity hypothesis for low-latitude glaciation near sea level during the Proterozoic ${ }^{2}$. He criticizes the 'snowball Earth' hypothesis ${ }^{3}$ on the grounds that global glaciation would be accompanied by drastic lowering of sea level. Sea level is lowered when ocean water is sequestered as land ice, but the volume of land ice that would exist in a 'snowball Earth' is uncertain because the hydrologic cycle would be severely reduced if the oceans were frozen over ${ }^{4}$.

There is clear evidence for emergence and hiatus during the Marinoan glaciation ( 600 Myr ago) in Australia 5 , "expressed by an erosional disconformity, in places with largescale channelling". The incised channels are $\sim 150$ metres deep $^{6}$, which would represent a minimum for the lowering of sea level assuming the land was depressed by glacial ice. This exceeds the lowering of sea level accompanying any Phanerozoic glaciation.

Williams ${ }^{1}$ points to the presence of seasonal freeze-thaw structures ${ }^{7}$, which he says could not form near the Equator because of low seasonal temperature variation. In fact, periglacial ice-wedge structures occur at $20^{\circ} \mathrm{N}$ latitude in Hawaii ${ }^{8}$ and near the Equator on Mount Kilimanjaro in Tanzania'. They are attributed to diurnal freeze-thaw cycles and may be shallower than those associated with the Marinoan glaciation ${ }^{7}$. Ice-wedge polygons are less well developed than linear ice wedges in the mountains because of surface slopes.

The 'snowball Earth' theory accounts for other features of the Neoproterozoic sedimentary record ${ }^{3}$ — banded iron formations, post-glacial cap carbonates, and large carbon-isotopic variations. The high-obliquity hypothesis provides no explanation for these features.

\section{Paul F. Hoffman}

Department of Earth Sciences, Harvard University, Cambridge, Massachusetts 02138, USA

1. Williams, G. E. Nature 398, 555-556 (1999).

2. Williams, G. E. Earth Sci. Rev. 34, 1-45 (1993).

3. Hoffman, P. F. et al. Science 281, 1342-1346 (1998).

4. Hoffman, P. F. \& Schrag, D. P. Science 284, 1087a (1999).

5. Preiss, W. V. Geol. Surv. S. Aust. Bull. 53, 438 (1987).

6. Dyson, I. A. \& von der Borch, C. C. in Incised-valley Systems: Origin and Sedimentary Sequences (eds Dalrymple, R. W. et al.) 209-222 (Soc. Sediment.Geol. Spec. Publ. 51, Tulsa, OK, 1994).

7. Williams, G. E. Precambrian Res. 32, 233-242 (1986).

8. Gregory, H. E. \& Wentworth, C. K. Bull. Geol. Soc. Am. 48, 1719-1742 (1937)

9. Downie, C. \& Wilkinson, P. The Geology of Kilimanjaro (Dept Geol., Univ. Sheffield, Sheffield, 1972).

\section{Visitheaven and hell} ahead of schedule

Sir - It is surprising to read that creationists in Kansas are lobbying the state board of education to include their views in school science teaching ${ }^{1}$. A literal reading of the Bible can sometimes be absurd, and it contains many numerical data that reflect only the views of an earlier age. These numbers can be the origin of funny calculations ${ }^{2}$. A colleague and I published a squib in which, using paragraphs from the biblical books of Isaiah and Revelation, the temperatures of heaven and hell were calculated as 504.5 and $716.6 \mathrm{~K}$ respectively ${ }^{3}$.

The calculation was discussed widely in the media. In the UK Sunday Times (9 August 1998), a geophysicist suggested possible locations, based on our results. Hell might be the hydrothermal vents on the bottom of the ocean, and heaven could be the thermosphere. It must be satisfying for creationists that such places can now be reached, thanks to the work of scientists.

\section{Jorge Mira-Pérez}

Departamento de Fisica Aplicada,

Universidade de Santiago de Compostela, E-15706 Santiago de Compostela, Spain

\footnotetext{
1. Dalton, R. Nature 398, 453 (1999).

2. Peil, K. Nature 399, 522 (1999).

3. Mira-Pérez, J. \& Vina, J. Physics Today 51 (7), 96 (1998).
} 